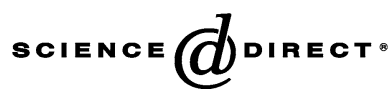

Journal of Microbiological Methods xx (2005) xxx-xxx

\section{Journal ${ }^{\text {of Microbiological }}$ Methods}

www.elsevier.com/locate/jmicmeth

\title{
Development of solution phase hybridisation PCR-ELISA for the detection and quantification of Enterococcus faecalis and Pediococcus pentosaceus in Nurmi-type cultures
}

\author{
Sinéad M. Waters ${ }^{\mathrm{a}, *}$, Sean Doyle ${ }^{\mathrm{b}}$, Richard A. Murphy ${ }^{\mathrm{a}}$, Ronan F.G. Power ${ }^{\mathrm{c}}$ \\ ${ }^{a}$ Alltech Ireland, Sarney, Summerhill Road, Dunboyne, Co. Meath, Ireland \\ ${ }^{\mathrm{b}}$ National Institute for Cellular Biotechnology, Department of Biology, National University of Ireland, Maynooth, Co. Kildare, Ireland \\ 'Alltech, Inc., 3031 Catnip Hill Pike, Nicholasville, KY 40356, USA
}

Received 2 December 2004; received in revised form 16 March 2005; accepted 29 March 2005

\begin{abstract}
Nurmi-type cultures (NTCs), derived from the fermentation of caecal contents of specifically pathogen-free (SPF) birds, have been used successfully to control salmonella colonisation in chicks. These cultures are undefined in nature and, consequently, it is difficult to obtain approval from regulatory agencies for their use as direct fed microbials (DFMs) for poultry. Progress towards the generation of effective defined probiotics requires further knowledge of the composition of these cultures. As such, species-specific, culture-independent quantification methodologies need to be developed to elucidate the concentration of specific bacterial constituents of NTCs. Quantification of specific bacterial species in such ill-defined complex cultures using conventional culturing methods is inaccurate due to low levels of sensitivity and reproducibility, in addition to slow turnaround times. Furthermore, these methods lack selectivity due to the nature of the accompanying microflora.

This study describes the development of a rapid, sensitive, reliable, reproducible, and species-specific culture-independent, solution phase hybridisation PCR-ELISA procedure for the detection and quantification of Enterococcus faecalis and Pediococcus pentosaceus in NTCs. In this technique, biotin-labelled primers were designed to amplify a species-specific fragment of a marker gene of known copy number, in both species. Resulting amplicons were hybridised with a dinitrophenol (DNP)-labelled oligonucleotide probe in solution and were subsequently captured on a streptavidin-coated microtitre plate. The degree of binding was determined by the addition of $\mathrm{IgG}$ (anti-DNP)-horseradish peroxidase conjugate, which was subsequently visualised using a chromogenic substrate, tetramethylbenzidine. This novel quantitative method was capable of detecting E. faecalis and P. pentosaceus at levels as low as 5 CFU per PCR reaction.
\end{abstract}

(c) 2005 Elsevier B.V. All rights reserved.

Keywords: Caecal contents; Enterococcus faecalis; Nurmi; PCR-ELISA; Pediococcus pentosaceus

\footnotetext{
* Corresponding author. Tel.: +3531 8252244; fax: +35318252246.

E-mail address: swaters@alltech.com (S.M. Waters).
} 


\section{Introduction}

Nurmi-type cultures (NTCs), derived from the fermentation of the mature caecal contents of specifically pathogen-free birds, have been successfully used to control salmonella colonisation in poultry (Bolder et al., 1992; Maciorowski et al., 1997; Stern et al., 2001). Caecal contents, from which these cultures are derived, are undefined (Salanitro et al., 1974; Zhu et al., 2002). As such, it is difficult to obtain approval from regulatory agencies to use these preparations as direct fed microbials (DFMs) for poultry. In an attempt to generate defined probiotics, several research groups have identified bacterial strains present in undefined gut microbiota and have used them singly or in mixtures to protect chicks against salmonella colonisation (Soerjadi et al., 1978; Weinack et al., 1985; Wierup et al., 1988; Stravic et al., 1991; Stravic, 1992). However, no defined product as effective as undefined gut microflora is available (Mead, 2000). A logical strategy is to generate defined probiotics, which are based on the relative concentrations in which constituent bacteria are present in effective NTCs. As a result, techniques are required to efficiently quantify specific bacterial species in these cultures.

Enterococcus faecalis is a key species in the development of certain fermented foods around the world (Hagrass et al., 1991; Franz et al., 1999; Elotmani et al., 2002), as well as playing important biological functions in the animal gut (Klein, 2003). The application of E. faecalis as a competitive exclusion agent and probiotic has been well reviewed in the literature (Pereira and Gibson, 2002; DeVuyst et al., 2003; Hufnagel et al., 2003). Specifically, E. faecalis has been documented to exhibit probiotic effects in the protection of chicks against Salmonalla typhimurium colonisation (Soerjadi et al., 1978) and also has the ability to protect epithelial cells against $S$. typhimurium invasion in vitro (Wagner et al., 2002). The potential of Pediococcus pentosaceus as a probiotic has also been well recognised (Mishra and Lambert, 1996; Gardiner et al., 2004; Lei and Jakobsen, 2004).

The quantification of specific bacterial species, especially those with certain physiological functions, in complex intestinal microbial populations has mainly been performed until now by culture-depend- ent techniques such as CFU determination on selective media (Tannock, 1999; Niamsup et al., 2003). Limitations associated with conventional culturing methods include low sensitivities (Dutta et al., 2001), inability to detect unculturable bacteria and unknown species, slow turnabout time, and poor reproducibility (Huijsdens et al., 2002). In addition, as large differences have been noted in the growth rates and growth requirements of different species, quantification by culture is highly likely to be inaccurate (Huijsdens et al., 2002). Furthermore, because of the ill-defined nature of the accompanying microbiota in NTCs, enumeration of specific species in such populations often proves problematic (O'Sullivan, 2000).

To overcome the problems associated with culturebased methodologies, culture-independent PCR has been applied to the quantification of specific genes as markers for bacterial presence (Bach et al., 2002). In a recent study, products generated from the amplification of a specific marker gene from bacterial cells could be visualised using ethidium bromide staining at levels of 50 CFU per PCR reaction (Daly et al., 2002). However, an increased level of detection was achieved by hybridisation of the PCR product with a species-specific labelled probe. Microwell ELISA-like hybridisation methods have therefore been developed (Nagata et al., 1985; van der Vliet et al., 1993; Gutierrez et al., 1998) and form the basis of convenient detection and quantification systems. In a solid phase PCR-ELISA methodology, Escherichia coli was detected in milk at levels as low as 5 CFU per PCR reaction (Daly et al., 2002). This technique involved the capture of $5^{\prime}$ biotin-labelled amplicons on streptavidin-coated microtitre plates followed by the subsequent addition of a dinitrophenol (DNP)labelled oligonucleotide probe to the plate where solid phase hybridisation occurred to detect the bound amplicons.

This study describes the development of a novel solution phase hybridisation PCR-ELISA system and its application in the detection and quantification of $E$. faecalis and P. pentosaceus species in two NTCs. The modification of PCR-ELISA to a solution phase hybridization method removed the necessity for separate amplicon attachment and DNP-labeled oligonucleotide probe binding steps as required in the solid phase approach, thus decreasing the turnabout time of the assay. A crucial requirement for this 
methodology to be analytically accurate was the confirmation of the species specificity and copy number of the targeted marker genes in both species.

\section{Materials and methods}

\subsection{Nurmi-type cultures and bacterial reference strains}

A lyophilised sample of a commercial NTC was supplied by Alltech, Inc. (Nicholasville, Kentucky, USA). Caecal contents $(1 \mathrm{~mL})$, obtained from pathogen-free adult birds, were cultured anaerobically at $37{ }^{\circ} \mathrm{C}$ for 3 days in $100 \mathrm{~mL}$ anaerobic Viande Levure (VL) (Barnes and Impey, 1971) broth, pH 6.7, with no agitation. An aliquot $(400 \mu \mathrm{L})$ of this culture was used to inoculate fresh anaerobic VL broth (400 $\mathrm{mL}$ ) and was incubated at $37{ }^{\circ} \mathrm{C}$, with no agitation for a further 4 days. Cells were collected by centrifugation at $6000 \mathrm{rpm}$ for $10 \mathrm{~min}$ using a MSE Mistral 1000 centrifuge (Shaw Scientific Ltd., Dublin, Ireland). Maltodextrin was added to generate a final concentration of $10 \%(\mathrm{wt} / \mathrm{wt})$ in caecal contents, and the pellet was frozen and lyophilised.

Previous culture-based studies identified accompanying Enterococcus species present in NTCs as Enterococcus faecium and Enterococcus avium. In the case of Pediococcus spp., Pediococcus acidilactici was the only additional Pediococcus sp. isolated from the NTC cultures (data not shown). Consequently, these species were selected as negative controls in species-specific PCR studies. As such, the pure strains, E. faecalis 775, E. avium 702691, E. faecium 700502, $P$. pentosaceus 7837 , and $P$. acidilactici 6990, obtained from NCIMB (National Collection of Industrial Food and Marine Bacteria, Aberdeen, Scotland, UK), were cultured according to the manufacturers' instructions. E. faecalis 775 and P. pentosaceus 7837, respectively, were employed as positive controls, while the remainder of strains were utilised as negative controls in species-specific PCR reactions.

\subsection{Species-specific amplification of marker gene fragments}

A number of methods of DNA preparation from NTCs and pure reference strains were assessed for optimal DNA recovery. The extraction of DNA using the Bacterial Genomic DNA Extraction kit (SigmaAldrich, St. Louis, Missouri, USA), according to the manufacturer's instructions, proved most effective at extracting the highest quality and quantity of DNA. Therefore, in this study, DNA was prepared from NTCs and pure strains using this technique. Biotinylated oligonucleotide primers (Sigma-Genosys, Cambridge, UK), 5'Enterof $\mathrm{F}$ and $3^{\prime}$ Enterof R (Table 1), were designed to amplify a 293 bp (position 64-356) region of the E. faecalis surface protein precursor gene (Genbank accession number AF034779). Biotinylated primers (Table 1), designated $5^{\prime}$ Pediop $\mathrm{F}$ and 3'Pediop R, were also designed to amplify a $321 \mathrm{bp}$ (position 25-345) fragment of the P. pentosaceus glutamate racemase gene (Genbank accession number L22448). Sequence analysis using the Basic Local Alignment Search Tool (BLAST), online at the National Centre for Biotechnology Information (NCBI) homepage (http://www.ncbi.nlm.nih.gov), confirmed the species specificity of these primers (data not shown). In addition, bioinformatic analysis ensured that the closest mismatches for the Enterof and the Pediop primers could not possibly be constituents of the NTCs (data not shown).

PCR reactions $(100 \mu \mathrm{L})$ contained $1 \mu \mathrm{g}$ of genomic DNA, $10 \times\left(\mathrm{NH}_{4}\right)_{2} \mathrm{SO}_{4}$ reaction buffer, $\mathrm{MgCl}_{2}$ (3 $\mathrm{mM}$ ), primers (500 ng each), and deoxynucleotide

Table 1

Primers and probes for solution phase hybridisation PCR-ELISA

\begin{tabular}{ll}
\hline Primer/probe designation & Sequence \\
\hline $5^{\prime}$ Enterof F & $5^{\prime}$ Biotin-GAAGGGAGCAAATTTAGTTTGTTTGGAAAAAACAATAAG-3' \\
$3^{\prime}$ Enterof R & $5^{\prime}$-ACATCACCAGTTATTGCTTTAGGG-3' \\
$5^{\prime}$ Pediop F & $5^{\prime}$ Biotin-GATGTATGTATAATTTTATTTAGTG-3' \\
$3^{\prime}$ Pediop R & $5^{\prime}$-CACCCCAATTACTGGGATGGGTAATTCAGCTTG-3' \\
DNP-EF & $5^{\prime}(\mathrm{DNP})_{3}$-CCCATTTGTGCATTAACTATTCCAGTTGCC-3' \\
DNP-PP & $5^{\prime}(\mathrm{DNP})_{3}$-ACGAGGACCATACGGCATTCTTGCTTCATC-3 \\
\hline
\end{tabular}


triphosphates (dNTPs) (500 $\mu \mathrm{M}$ each). Taq DNA polymerase (2U) (Bioline $^{\mathrm{TM}}$, London, UK) was added following the initial denaturation step. Each PCR reaction consisted of $94{ }^{\circ} \mathrm{C}$ for 2 min and 40 cycles of $93{ }^{\circ} \mathrm{C}$ for $30 \mathrm{~s}, 64^{\circ} \mathrm{C}$ for $30 \mathrm{~s}, 72{ }^{\circ} \mathrm{C}$ for $30 \mathrm{~s}$, followed by $10 \mathrm{~min}$ at $72{ }^{\circ} \mathrm{C}$. Analysis of amplified PCR products was carried out on a $1 \%(\mathrm{wt} / \mathrm{vol})$ agarose gel using $1 \times$ Tris acetate EDTA (TAE) running buffer, $\mathrm{pH}$ 8.3. To confirm the identity of amplified fragments and species specificity of the primers, PCR products generated from both NTCs and pure reference strains were subcloned into a plasmid shuttle vector ( $\mathrm{pCR}$ $2.1^{\mathrm{TM}}$ ) (Invitrogen, Carlsbad, California, USA) and $E$. coli strain INV $\alpha \mathrm{F}^{\prime}$ competent cells (Invitrogen, Carlsbad, California, USA) were transformed. Sequencing of insert DNA was carried out by Oswel (Southampton, UK), using M13 forward and reverse sequencing primers. Analysis of sequence data and homology comparisons was performed using BLAST, online at the NCBI homepage (http://www.ncbi.nlm. nih.gov).

\subsection{Determination of marker gene copy number}

Confirmation of copy number was achieved by Southern blot hybridisation analysis using a previously described method (Kim et al., 1999; Vassileva et al., 2001). To assess the copy number of the marker genes targeted in respective E. faecalis or $P$. pentosaceus, standard curves of known marker gene copy number were generated. Marker gene fragments were subcloned into a plasmid vector ( $\mathrm{pCR} 2.1^{\mathrm{TM}}$ ) (Invitrogen, Carlsbad, California, USA) and the shuttle construct then contained one copy of the gene fragment. Plasmid constructs were linearised using the restriction enzyme BamHI, for which no restriction site exists in the E. faecalis or $P$. pentosaceus marker genes. E. faecalis and $P$. pentosaceus genomic DNA were subjected to a double restriction enzyme digestion. BstEII and BamHI were employed in the case of E. faecalis genomic DNA, and EcoRI and Bam $\mathrm{HI}$ for P. pentosaceus. Various quantities of digested genomic DNA (ranging from $0.01 \mu \mathrm{g}$ to 10 $\mu \mathrm{g})$ and dilutions of linearised plasmid shuttle vector construct $\left(10^{11}, 10^{10}\right.$, and $10^{9}$ copies of the $E$. faecalis or $P$. pentosaceus marker gene fragments, respectively) were electrophoresed on a $1 \%(\mathrm{wt} / \mathrm{vol})$ agarose gel for $20 \mathrm{~h}$ at $4{ }^{\circ} \mathrm{C}$. Capillary blotting onto a nitrocellulose membrane (Millipore, Bedford, Massachusetts, USA) was carried out as outlined by the manufacturer. E. faecalis and P. pentosaceus marker gene fragments were used as template DNA in the production of biotin-labelled Southern hybridisation probes using the Random Primer DNA Biotinylation kit (Pall Gelman Laboratories, Ann Arbor, Michigan, USA). Hybridisation and detection of marker gene fragments were performed using the DNA Hybridisation and Detection kit (Pall Gelman Laboratories, Ann Arbor, Michigan, USA). Exposure to X-ray film produced a permanent record of chemiluminescent emissions. Analysis of signal intensities of bands on the Southern hybridisation blot was performed using the Bio ID Gel Documentation and Densitometry system (Vilber Lourmat, Cedex, France). Signal intensities obtained from genomic DNA were subsequently related to those generated from standards of known gene copy number.

\subsection{Solution phase hybridisation PCR-ELISA}

KF Streptococcus and Raka ray number 3 broths were used to culture E. faecalis and $P$. pentosaceus, respectively. Serial dilutions of overnight cultures of $E$. faecalis and $P$. pentosaceus in their respective sterile culture media were carried out. An aliquot (100 $\mu \mathrm{L}$ ) of each dilution of both species was plated, in triplicate, on KF Streptococcus agar for E. faecalis and on Raka-ray no. 3 agar for $P$. pentosaceus. KF Streptococcus agar plates were incubated at $37{ }^{\circ} \mathrm{C}$ for 2 days, while Raka-ray no. 3 plates were incubated at $30{ }^{\circ} \mathrm{C}$ for 3 days. Blank culture media was employed as a negative control. Colony counting was performed using an Eagle-Eye II gel documentation system (Stratagene, La Jolla, CA, USA). These same overnight cultures of $E$. faecalis and $P$. pentosaceus cultures were diluted to generate standards containing 0-5000 CFU, for each species.

DNA, extracted from dilutions of $E$. faecalis and $P$. pentosaceus, was subjected to PCR amplification. Subsequent amplicons were used to produce standard curves for the solution phase hybridisation PCRELISA systems. As such, biotinylated PCR products were generated from $P$. pentosaceus and E. faecalis CFU standards (0-5000 CFU), along with dilutions $\left(10 \mu \mathrm{g} \mathrm{mL}^{-1}, 100 \mu \mathrm{g} \mathrm{mL}^{-1}, 1 \mathrm{mg} \mathrm{mL}{ }^{-1}, 10 \mathrm{mg}\right.$ $\mathrm{mL}^{-1}$, and $100 \mathrm{mg} \mathrm{mL}{ }^{-1}$ ) of NTCs. All PCR- 
amplified products from NTCs were analysed on a $1 \%$ (wt/vol) agarose gel together with the respective $E$. faecalis or $P$. pentosaceus PCR-generated standards. This was performed to estimate the approximate concentration of NTC, which yielded amplicons within the concentration range of the PCR-ELISA standard curve.

ELISA was carried out on PCR products as described by Daly et al. (2002) with the modifications outlined below. It will be recalled that modification of PCR-ELISA technique to a solution phase hybridization method removed the necessity for the separate PCR product attachment and DNPlabelled oligonucleotide probe binding steps as required in the solid phase approach. E. faecalis and $P$. pentosaceus-specific (DNP) $)_{3}$-labelled oligonucleotide probes [DNP-EF for the detection of $E$. faecalis and DNP-PP for P. pentosaceus (Table 1), designed and confirmed to be species-specific using BLAST analysis, online at the NCBI homepage (http://www.ncbi.nlm.nih.gov)], were diluted in $6 \times$ SSC $0.1 \%$ (wt/vol) sodium dodecyl sulphate (SDS) to yield a final concentration of $10 \mu \mathrm{g} \mathrm{mL} \mathrm{m}^{-1}$ $(\mathrm{DNP})_{3}$-labelled oligonucleotide probe.

Probes were heat-denatured at $95{ }^{\circ} \mathrm{C}$ for $10 \mathrm{~min}$ and placed directly on ice. An aliquot $(10 \mu \mathrm{L})$ of the $(\mathrm{DNP})_{3}$-labelled oligonucleotide probe was added to the denatured biotinylated PCR products. Tubes were mixed by vortexing and the biotinylated PCR products and $(\mathrm{DNP})_{3}$-labelled oligonucleotide probe were allowed to hybridise for $1 \mathrm{~h}$ at $37{ }^{\circ} \mathrm{C}$. Following hybridisation, the contents of the tubes were added to the streptavidin-coated microtitre plate. To generate a standard curve for E. faecalis/P. pentosaceus quantification, CFU values were subjected to a log transformation and $A_{450 / 630 \mathrm{~nm}}$ values were plotted against the $\log$ transformation of $\mathrm{CFU}$ values.

\subsection{Examination of linearity of dilution and reprodu- cibility of the PCR-ELISA systems}

To examine the linearity of dilution of the assays, further dilutions $(1: 2,1: 5,1: 10$, and 1:100) of $10 \mathrm{mg}$ $\mathrm{mL}^{-1}$ commercial NTC and cultured caecal contents were performed in $0.1 \%(\mathrm{wt} / \mathrm{vol})$ peptone water. Samples of these dilutions were subjected to DNA extraction and subsequent PCR amplification. ELISA was performed on all amplicons. In addition, the reproducibility of the assay was assessed by measuring the concentration of E. faecalis in the same cultured caecal contents sample, using the entire solution phase PCR-ELISA procedure, on three separate occasions.

\section{Results}

\subsection{Species-specific amplification of marker gene fragments}

PCR products of approximately $300 \mathrm{bp}$ were amplified from the commercial NTC, cultured caecal contents and the positive control strains using the Enterof and Pediop primers (Fig. 1(a) and (b)), respectively. No amplification was evident from the negative controls for both species (i.e., E. faecium and E. avium for Enterof primers and P. acidilactici for Pediop primers). The species specificity of the Enterof and Pediop primers was further confirmed by sequence analysis of the amplified products from both the NTCs and the positive control strains. Results showed that amplicons exhibited $100 \%$ sequence homology (293/293) to the E. faecalis genome (Genbank accession numbers AF034779, AY032999, AF454824, and AF329367) and the P. pentosaceus glutamate racemase gene (321/321) (Genbank accession numbers L22448 and L22789), respectively (data not shown). Bioinformatic analysis also confirmed that the homology mismatches for these amplicons, if any, could not possibly be constituents of the NTCs (data not shown). Indeed, these data also confirm the efficiency of the primers' ability to specifically amplify regions of the E. faecalis or $P$. pentosacues genomes from complex NTC cultures.

\subsection{Determination of copy number of marker genes}

Various quantities of digested genomic DNA (ranging from $0.01 \mu \mathrm{g}$ to $10 \mu \mathrm{g}$ ) and dilutions of linearised plasmid shuttle vector construct $\left(10^{11}, 10^{10}\right.$, and $10^{9}$ copies of the E. faecalis or P. pentosaceus marker gene fragments, respectively) were subjected to Southern blot hybridisation analysis. A single band of $8 \mathrm{~kb}$ was detected only in the lanes containing 10 $\mu \mathrm{g}$ and $5 \mu \mathrm{g}$ of $E$. faecalis genomic DNA, previously digested with BstEII and BamHI (Fig. 2(a), lanes 1 
(a)

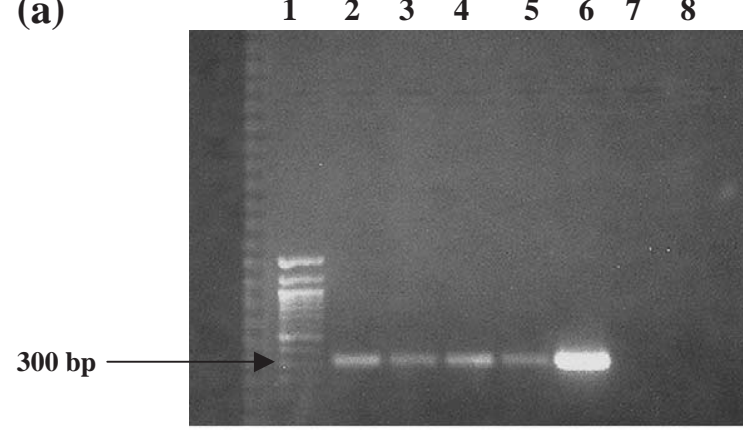

(b)

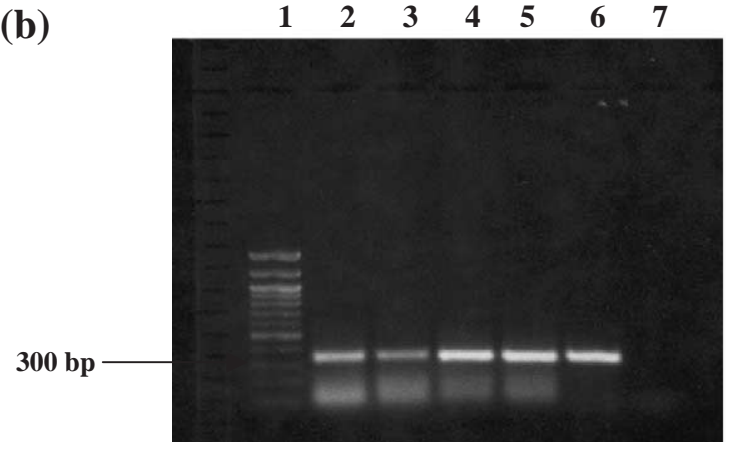

Fig. 1. (a) Enterococcus faecalis-specific PCR. Lane 1: $100 \mathrm{bp}$ marker; lane 2: commercial NTC; lane 3: cultured caecal contents; lane 4: E. faecalis isolated from commercial NTC; lane 5: E. faecalis isolated from cultured caecal content; lane 6: E. faecalis 775; lane 7: E. faecium 700502; lane 8: E. avium 702691. (b) Pediococcus pentosaceus-specific PCR. Lane 1: 100 bp marker; lane 2: commercial NTC; lane 3: cultured caecal content; lane 4: $P$. pentosaceus isolated from NTC; lane 5: P. pentosaceus isolated from cultured caecal content; lane 6: P. pentosaceus 7837; lane 7: $P$. acidilactici 6990. NTC: Nurmi-type culture.

and 2) but was not detected in the lanes containing lesser quantities of DNA. By similar analysis of the plasmid DNA standards, a detectable signal was observed in lanes containing $10^{11}, 10^{10}$, and $10^{9}$ copies of the E. faecalis surface protein precursor gene fragment (Fig. 2(a), lanes 11, 12, and 13). Lanes containing $10 \mu \mathrm{g}$ and $5 \mu \mathrm{g}$ of restricted $P$. pentosaceus genomic DNA exhibited a single band of $1 \mathrm{~kb}$ (Fig. 2(b), lanes 1 and 2); however, no band was detected in the lanes containing lesser quantities of genomic DNA. As with E. faecalis, Southern hybridisation analysis of the plasmid DNA standards yielded a signal in lanes containing $10^{11}, 10^{10}$, and $10^{9}$ copies of the $P$. pentosaceus glutamate racemase gene fragment (Fig. 2(b), lanes 7, 8, and 9). Densitometry was used to relate the signal intensities of the plasmid DNA standards to those obtained from E. faecalis and $P$. pentosaceus genomic DNA. Standard curves were constructed by plotting the signal intensities of the bands generated from the plasmid DNA standards against the log transformation of copy number. Using the signal intensity values obtained for $10 \mu \mathrm{g}$ and $5 \mu \mathrm{g}$ of E. faecalis and P. pentosaceus genomic DNA and the equation of the standard curves, it was confirmed that both the E. faecalis surface protein precursor gene and the $P$. pentosaceus glutamate racemase gene were indeed single copy.

\subsection{Solution phase hybridisation PCR-ELISA analysis}

Elucidation of the copy number of marker genes in E. faecalis and P. pentosaceus facilitated the development of a solution phase hybridisation PCR-ELISA for the detection and quantification of these species in undefined NTCs. Examination of E. faecalis- and $P$. pentosaceus-specific amplicons produced by the commercial NTC and cultured caecal contents indicated that $P$. pentosaceus was harboured at lower concentrations than E. faecalis in both these cultures. Indeed, visual inspection of the ethidium bromidestained agarose gels indicated that the limit of reliable detection of $E$. faecalis or $P$. pentosaceus was approximately $5 \times 10^{2} \mathrm{CFU}$ per PCR reaction. Moreover, optimisation of sample dilution of NTCs determined that $10 \mathrm{mg} \mathrm{mL}^{-1}$ NTC samples $(100 \mu \mathrm{g}$ equivalent per PCR reaction) yielded PCR amplicons falling within the range for the E. faecalis and $P$. pentosaceus standards (data not shown).

Amplified biotinylated PCR products were further analysed by ELISA to improve the detection limit of amplicons. For pure strain standards, CFU values

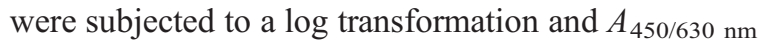
values were plotted against the log transformation of CFU values to produce standard curves for E. faecalis and P. pentosaceus, respectively (Fig. 3(a) and (b)). It was established that solution phase hybridisation PCR-ELISA was extremely sensitive, detecting bacteria at levels as low as 5 CFU per PCR reaction. The standard curves were subsequently used to quantify the levels of E. faecalis and P. pentosaceus, respectively, in the commercial NTC and cultured caecal contents. E. faecalis- and P. pentosaceus-specific 

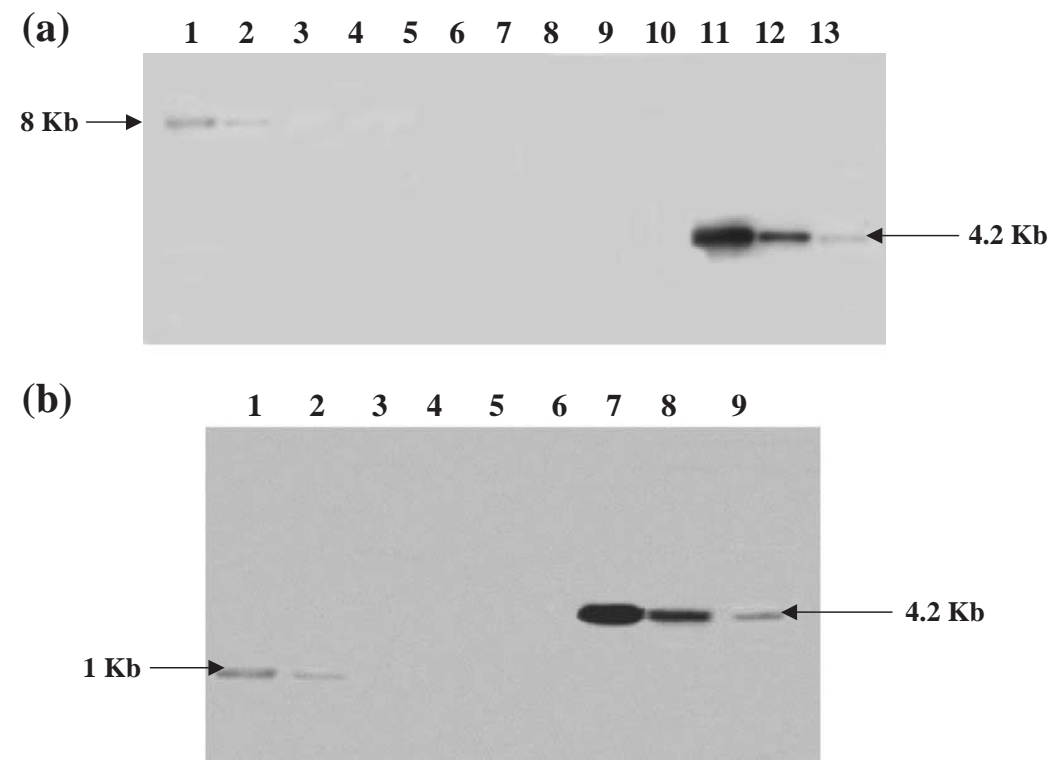

Fig. 2. (a) Southern blot hybridisation analysis of the E. faecalis surface protein precursor gene fragment. Lane 1: $10 \mu \mathrm{g}$; lane 2: $5 \mu \mathrm{g}$; lane 3: 1 $\mu \mathrm{g}$; lane 4: $0.5 \mu \mathrm{g}$; lane 5: $0.1 \mu \mathrm{g}$; lane 6: $0.05 \mu \mathrm{g}$; lane 7: $0.01 \mu \mathrm{g}$ of E. faecalis genomic DNA; lane 11: $10^{11}$ copies of the E. faecalis surface protein precursor gene fragment (marker gene); lane 12: $10^{10}$ copies of the marker gene; lane 13: $10^{9}$ copies of the marker gene. (b). Southern blot hybridisation analysis of the $P$. pentosaceus glutamate racemase gene fragment. Lane 1: $10 \mu \mathrm{g}$; lane 2: $5 \mu \mathrm{g}$; lane 3: $1 \mu \mathrm{g}$; lane 4: $0.5 \mu \mathrm{g}$; lane 5: $0.1 \mu \mathrm{g}$; lane 6: $0.05 \mu \mathrm{g}$ of P. pentosaceus genomic DNA; lane 7: $10^{11}$ copies of the P. pentosaceus glutamate racemase gene fragment (marker gene); lane 8: $10^{10}$ copies of the marker gene; lane 9: $10^{9}$ copies of the marker gene.

PCR-ELISA analysis of the commercial NTC and cultured caecal contents was carried out in triplicate and results were expressed as the mean \pm S.E.M. (Table 2).

\subsection{Examination of linearity of dilution and reprodu- cibility of the PCR-ELISA systems}

The linearity of dilution of the assay was examined by performing further dilutions of NTCs. Resultant dilutions were subjected to DNA extraction and PCR. Solution phase hybridisation PCR-ELISA was subsequently performed on these amplicons. At concentrations as low as $100 \mu \mathrm{g} \mathrm{mL}^{-1}(1 / 100$ dilution of 10 $\mathrm{mg} \mathrm{mL}^{-1}$ ) commercial NTC and cultured caecal contents, E. faecalis and P. pentosaceus were detected in these cultures. When these values were compared to those obtained for $10 \mathrm{mg} \mathrm{mL}^{-1}$ commercial NTC and cultured caecal contents (Fig. 4(a) and (b)), the results concur. Results obtained were therefore shown to be independent of the dilution at which the sample was assayed, once the dilution factor was taken into account. Furthermore, the reproducibility of the assay was assessed. When E. faecalis was measured in the same cultured caecal contents sample, employing the entire solution phase PCR-ELISA procedure, on three separate occasions, results were as follows: $1.4 \pm$ $0.0056 \times 10^{8}, 1.3 \pm 0.01 \times 10^{8}$, and $1.3 \pm 0.013 \times 10^{8}$ $\mathrm{CFU} \mathrm{g} \mathrm{g}^{-1}$. These findings confirm that solution phase hybridisation PCR-ELISA is a reproducible and sensitive method of quantifying specific bacteria in mixed cultures.

\section{Discussion}

A novel, rapid, sensitive, and reproducible PCRELISA system has been developed for the specific detection and quantification of $E$. faecalis and $P$. pentosaceus in NTCs. This is the first report of a solution phase hybridisation PCR-ELISA technique that employs the use of biotin-labelled primers and DNP-labelled oligonucleotide probes. The methodology is culture-independent and extremely sensitive, detecting bacteria present at levels as low as $5 \mathrm{CFU}$ per PCR reaction. Historically, the quantification of 

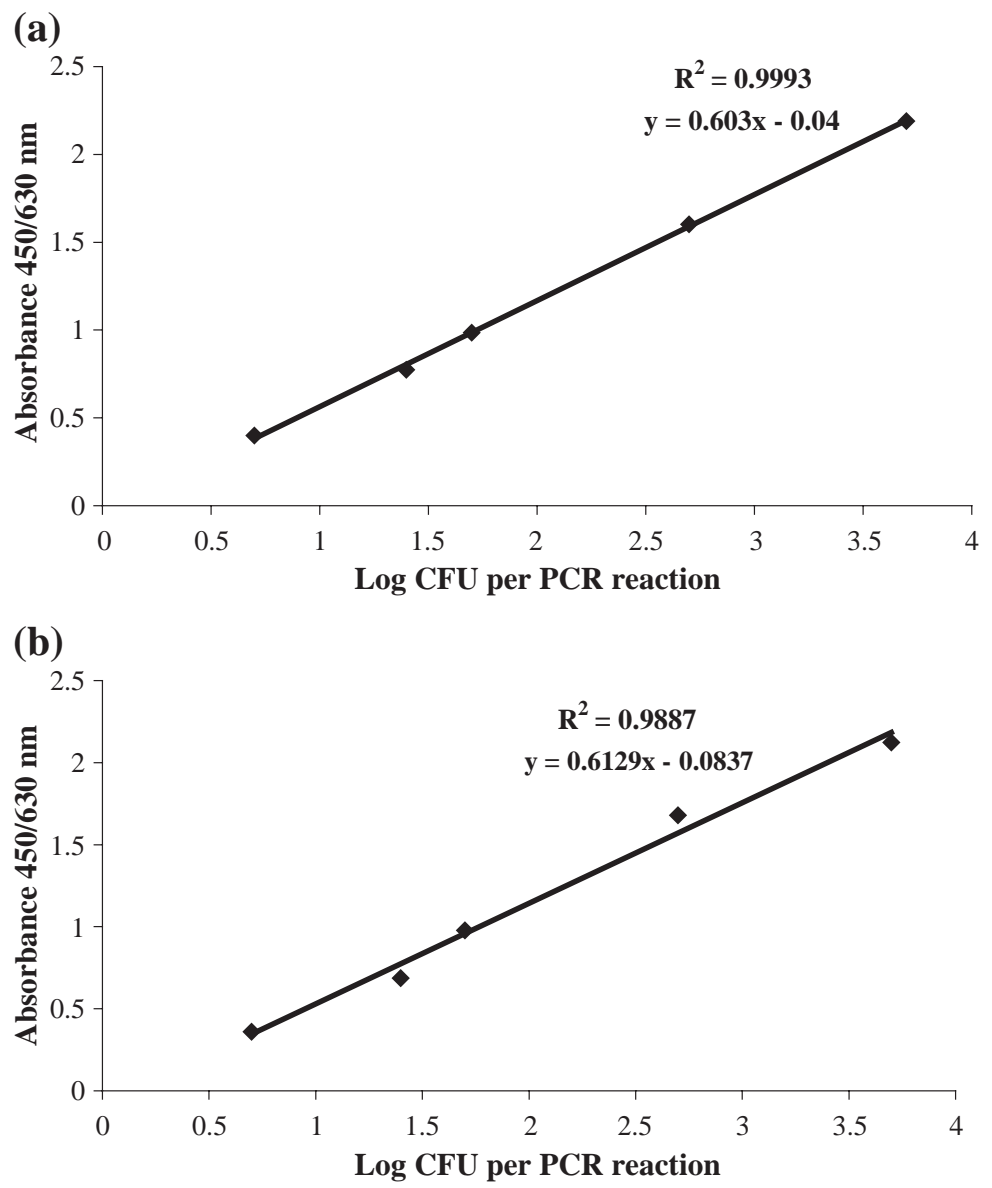

Fig. 3. (a) Standard curve for E. faecalis quantitation. (b) Standard curve for P. pentosaceus quantitation.

microorganisms in complex samples, such as NTCs, has generally been performed by culture-dependent techniques. While KF Streptococcus and Raka ray number 3 agars, for example, are commonly used growth media for enterococci and pediococci, respectively, there are no reports in the literature of selective agars that enumerate E. faecalis or P. pentosaceus in complex mixed cultures.

To facilitate the development of the PCR-ELISA technique, it was initially necessary to determine the species-specificity and the copy number of the genes targeted in this study. PCR of genomic DNA from positive and negative control strains and subsequent sequence analysis of the amplified products indicated the species-specificity of the primers designed in this study (Fig. 1(a) and (b)). Southern hybridisation analysis of both E. faecalis and P. pentosaceus genomes (Fig. 2(a) and (b)), using probes homologous to the putative single copy genes (E. faecalis surface protein precursor gene and the $P$. pentosaceus glutamate racemase gene), confirmed that these were indeed present as single copy genes in the respective bacteria. No previous report exists in the literature of these genes being encoded by a single copy and this result allowed the development of a solution phase hybridisation PCR-ELISA assay for the quantification of E. faecalis and P. pentosaceus in NTCs. Indeed, using this information, a direct correlation between copy number detected and CFU could be made.

Although a number of gel staining methods are available (e.g., SYBR green, ethidium bromide, and silver staining), ethidium bromide is still the stain most commonly used for agarose gels. Employing agarose gel electrophoresis and ethidium bromide 
Table 2

Solution phase hybridisation PCR-ELISA quantitation of E. faecalis and P. pentosaceus

\begin{tabular}{lllll}
\hline Species & Culture type & $A_{450 / 630 \mathrm{~nm}}$ & Log CFU per $100 \mu \mathrm{g}$ & CFU g $^{-1}$ \\
\hline E. faecalis & CNTC & $2.25 \pm 0.02$ & 3.80 & $6.3 \times 10^{7}$ \\
E. faecalis & CCC & $2.47 \pm 0.01$ & 4.16 & $1.4 \times 10^{8}$ \\
$P$. pentosaceus & CNTC & $1.10 \pm 0.02$ & 1.93 & $8.5 \times 10^{5}$ \\
$P$. pentosaceus & CCC & $1.48 \pm 0.03$ & 2.55 & $3.5 \times 10^{6}$ \\
\hline
\end{tabular}

Absorbance values are expressed as a mean of PCR-ELISA analysis of three replicates of the same culture sample \pm S.E.M. CFU, colonyforming units; CNTC, commercial Nurmi-type culture; CCC, cultured caecal contents.

staining, the limit of reliable detection of E. faecalis or $P$. pentosaceus within a sample was approximately $5 \times 10^{2}$ CFU per PCR reaction. However, the lack of sensitivity, the subjectivity of band identification, and the use of the carcinogenic DNA binding agent, ethidium bromide, are some of the problems associated with agarose gel electrophoresis. Utilising the novel solution phase hybridisation PCR-ELISA system, E. faecalis and P. pentosaceus were detected at levels as low as 5 CFU per PCR reaction (Fig. 3(a) and (b), respectively). A solid phase hybridisation PCR-ELISA method has been employed to detect $E$. coli in milk at levels between 5 and 50 CFU per PCR reaction (Daly et al., 2002). In addition, a similar system described elsewhere was capable of detecting 1-10 salmonella bacterial cells in $25 \mathrm{~g}$ of meat (Delibato et al., 2001). Moreover, in a study where Listeria monocytogenes was measured in sewage

\section{(a) Linearity of Dilution - Enterococcus faecalis}

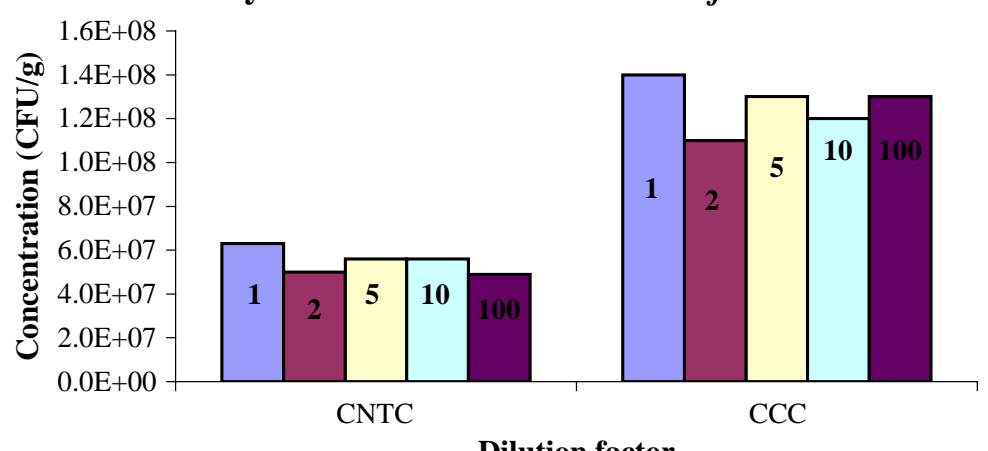

\section{(b) Linearity of Dilution - Pediococcus pentosaceus}

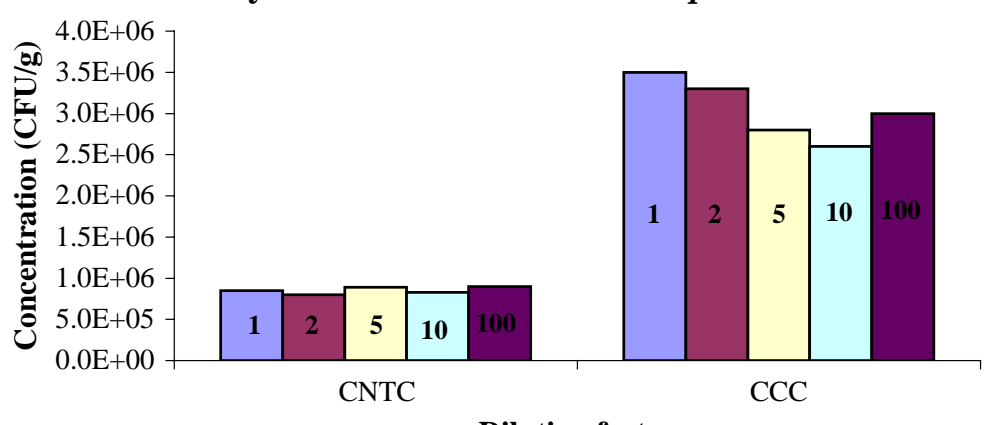

Dilution factor

Fig. 4. Examination of the linearity of dilution of solution phase hybridisation PCR-ELISA quantification of (a) E. faecalis and (b) $P$. pentosaceus in NTCs. CNTC; commercial Nurmi-type culture; CCC; cultured caecal contents. 
sludge, PCR-ELISA was effective in detecting less than 10 CFU per PCR reaction (Garrec et al., 2003).

Once developed, it was essential to demonstrate both the linearity of dilution and the reproducibility of the novel solution phase hybridisation PCR-ELISA system. Quantitation was shown to be independent of the dilution at which the sample was assayed, once the dilution factor was taken into consideration (Fig. 4(a) and (b)). To further confirm the reproducibility of the methodology, a sample of NTC was assayed a number of times and was found to generate the same result.

The main disadvantage associated with culturing as a quantitation method is the turnabout time that may extend to many days in certain cases. The use of solution phase hybridisation PCR-ELISA, however, can circumvent this problem. The PCR is completed in $2 \mathrm{~h}$ and the subsequent ELISA step only takes approximately $2 \mathrm{~h}$ and $30 \mathrm{~min}$, a low turnaround time compared to several days with culturing.

A popular alternative technique employed in the quantification of bacteria in complex environments is real-time PCR technology. The solution phase hybridisation PCR-ELISA generated results, which are comparable to those obtained from real-time PCR analyses for other microorganisms, with regard to sensitivity. In a study carried out on the quantification of Campylobacter lanienae in bovine feces by realtime PCR, the limit of reliable quantification was one to eight genomes (Inglis and Kalischuk, 2004). The use of real-time PCR as a tool to study the gastrointestinal microbiota that adheres to the colonic mucosa was also evaluated (Huijsdens et al., 2002). The assay, employing probes and primers targeting the 16S rRNA gene, proved to be very sensitive as levels as low as 1 CFU E. coli and 9 CFU Bacteroides vulgatus could be detected. However, multicopy $16 \mathrm{~S}$ rRNA genes were targeted in this instance and, as a result, the methodology is not absolutely quantitative. Alternatively, the PCR-ELISA method is more straightforward and does not require the use of expensive equipment, as does real-time PCR. In addition, automation of multiple sample analysis can be easily performed on streptavidin-coated microtitre plates whereas real-time PCR sample analysis is sequential.

While it has been shown that pediococci and enterococci inhabit the gut microbiota of poultry (Kurzak et al., 1998; Niamsup et al., 2003; Jackson et al., 2004), no data exist on the concentrations at which E. faecalis and P. pentosaceus exist in NTCs. Standard microbiological techniques were used to enumerate the total enterococcal population in these NTCs using KF Streptococcus agar. Results of $1.9 \times 10^{7} \mathrm{CFU} \mathrm{g}^{-1}$ and $1.2 \times 10^{8} \mathrm{CFU} \mathrm{g}^{-1}$ total enterococci in the commercial NTC and cultured caecal contents, respectively, were obtained using this method (data not shown). Elsewhere, enterococci were shown to exist in caecal contents of chicks at a concentration of $1.32 \times 10^{8} \mathrm{CFU} \mathrm{g}^{-1}$ (Spring et al., 2000). Another group, analyzing the development of caecal microbiota in chickens during growth, noted that on day 35 , chicks contained an average of $10^{7}$ CFU g ${ }^{-1}$ enterococci (van der Wielen et al., 2000). These findings correlate with our results from culturing studies. However, it was surprising to note that using solution phase hybridisation PCR-ELISA to quantify one constituent enterococcal species, $E$. faecalis, in these cultures, slightly higher levels were recorded (i.e., $6.3 \times 10^{7} \mathrm{CFU} \mathrm{g}^{-1}$ and $1.4 \times 10^{8} \mathrm{CFU}$ $\mathrm{g}^{-1}$, respectively) (Table 2 ). In addition, the concentrations of $P$. pentosaceus in the commercial NTC and cultured caecal contents were determined as $8.5 \times 10^{5}$ $\mathrm{CFU} \mathrm{g}{ }^{-1}$ and $3.5 \times 10^{6} \mathrm{CFU} \mathrm{g}^{-1}$, respectively (Table 2 ), using the PCR-ELISA method. Considering that the total lactic acid bacterial concentration, determined using Raka ray number 3 agar, in these preparations was $1.2 \times 10^{6} \mathrm{CFU} \mathrm{g}^{-1}$ and $1.2 \times 10^{7}$ $\mathrm{CFU} \mathrm{g} \mathrm{g}^{-1}$ (data not shown), respectively, the counts generated for $P$. pentosaceus alone using PCR-ELISA also seem quite high in comparison.

It has been observed that a variety of agars contain compounds that prove toxic to certain groups of bacteria (Silvi et al., 1996; O'Sullivan, 2000). In addition, there is a requirement that all bacterial cells present in the culture produce morphologically distinct colonies when cultured on solid media. However, not all microbial cells are present in a physiological state which is conducive to growth. In contrast to the culture-dependent technique, solution phase hybridisation PCR-ELISA is culture-independent and extremely sensitive, detecting bacteria present at levels as low as 5 CFU per PCR reaction. Additionally, in order to overcome the likely limitation of DNA amplification from dead cells, it may be possible in some instances to use reverse transcriptase PCR in conjunction with solution phase 
hybridisation PCR-ELISA to distinguish between viable and non-viable cells.

The technology described in this study has immense application in the area of defined probiotic production. Once the composition of an effective NTC is established using such techniques, defined probiotics may be generated based on relative concentrations of constituents. Of note, however, is the potential pathogenicity of enterococci, particularly $E$. faecalis, and their ability to serve as hosts and/or donors of transferable genes encoding antibiotic resistance (Franz et al., 1999). As a result, it appears that this species ideally should not be included as a constituent species of a defined probiotic preparation. However, it will be recalled that a gene of known copy number (i.e., single copy) was identified in E. faecalis, underscoring its suitability in the development of the solution phase hybridisation PCR-ELISA system.

This methodology also has tremendous application for monitoring alterations in the concentration of specific species in gut microbiota with changes in age and diet, and over time. It may be employed in the area of food-borne pathogenesis where the rapid identification of species, such as salmonella, in food is of utmost importance. As PCR-ELISA will circumvent time limitations associated with conventional culturing methods, it may also have an application in the diagnosis of disease where the sensitivity and speed at which this method may be performed are also of benefit.

\section{Acknowledgments}

Financial support for this work was provided by Alltech Ireland Ltd. The authors would like to acknowledge the advice of Dr. Paul Daly in the development of the solution phase hybridisation PCRELISA assays.

\section{References}

Bach, H.J., Tomanova, J., Schloter, M., Munch, J.C., 2002. Enumeration of total bacteria and bacteria with genes for proteolytic activity in pure cultures and in environmental samples by quantitative PCR-mediated amplification. J. Microbiol. Methods 49, 235-245.
Barnes, E.M., Impey, C.S., 1971. The isolation of the anaerobic bacteria from chicken caeca with particular reference to members of the family Bacteroidaceae. In: Shapton, D.A., Board, R.G. (Eds.), Isolation of Anaerobes, Symposium XIII. Tech. Series No. 5. The Society for Applied Bacteriology, New York, pp. 115-123.

Bolder, N.M., van Lith, L.A., Putirulan, F.F., Jacobs-Reitsma, W.F., Mulder, R.W., 1992. Prevention of colonisation of Salmonella eneritidis PT4 in broiler chickens. Int. J. Food Microbiol. 15, $313-317$.

Daly, P., Collier, T., Doyle, S., 2002. PCR-ELISA detection of Escherichia coli in milk. Lett. Appl. Microbiol. 34, 222-226.

Delibato, E., Suffredini, E., Volpe, G., De Medici, D., Palleschi, G., Croci, L., 2001. Development of rapid methods for the determination of salmonella in meat products. Proceedings of the 4th Annual Symposium on Epidemiology and Control of Salmonella and Other Foodborne Pathogens in Pork. University of Leipzig, Leipzig, Germany, pp. 601-603.

DeVuyst, L., Foulquie Moreno, M.R., Revets, H., 2003. Screening for enterocins and detection of hemolysin and vancomycin resistance in enterococci of different origins. Int. J. Food Microbiol. 84, 299-318.

Dutta, S., Chatterjee, A., Dutta, P., Rajendran, K., Roy, S., Pramanik, K.C., Bhattacharya, S.K., 2001. Sensitivity and performance characteristics of direct stool samples in comparison to conventional techniques for diagnosis of Shigella and enteroinvasive Escherichia coli infection in children with acute diarrhoea in Calcutta, India. J. Med. Microbiol. 50, 667-674.

Elotmani, F., Revol-Junelles, A.M., Assobhei, O., Milliere, J.B., 2002. Characterization of anti-Listeria monocytogenes bacteriocins from Enterococcus faecalis, Enterococcus faecium, and Lactococcus lactis strains isolated from RaÃ b, a Moroccan traditional fermented milk. Curr. Microbiol. 44, 10-17.

Franz, C.M., Holapfel, W.H., Stiles, M.E., 1999. Enterococci at the crossroads of food safety? Int. J. Food Microbiol. 47, 1-24.

Gardiner, G.E., Casey, P.G., Casey, G., Lynch, P.B., Lawlor, P.G., Hill, C., Fitzgerald, G.F., Stanton, C., Ross, R.P., 2004. Relative ability of orally administered Lactobacillus murinus to predominate and persist in the porcine gastrointestinal tract. Appl. Environ. Microbiol. 70, 1895-1906.

Garrec, N., Dilasser, F., Pourcher, A.M., Perelle, S., Fach, P., 2003. Comparison of a cultural method with ListerScreen plus Rapid'L.mono or PCR-ELISA methods for the enumeration of L. monocytogenes in naturally contaminated sewage sludge. J. Microbiol. Methods 55, 763-773.

Gutierrez, R., Garcia, T., Gonzalez, I., Sanz, B., Hermandez, P.E., Martin, R., 1998. Quantitative detection of meat spoilage bacteria by using the polymerase chain reaction (PCR) and an enzyme linked immunosorbent assay (ELISA). Lett. Appl. Microbiol. 26, 372-376.

Hagrass, A.E., Fayed, E.O., Aly, A.A., el-Samragy, Y.A., 1991. Growth characteristics of enterococci isolated from Laban Rayeb. Nahrung 35, 209-213.

Hufnagel, M., Koch, S., Kropec, A., Huebner, J., 2003. Opsonophagocytic assay as a potentially useful tool for assessing safety of enterococcal preparations. Int. J. Food Microbiol. 88, $263-267$. 
Huijsdens, X.W., Linskens, R.K., Mak, M.S., Meuwissen, G.M., Vankenbroucke-Grauls, C.M.J.E., Savelkoul, P.H.M., 2002. Quantification of bacteria adherent to gastrointestinal mucosa by real-time PCR. J. Clin. Microbiol. 40, 4423-4427.

Inglis, G.D., Kalischuk, L.D., 2004. Direct quantification of Campylobacter jejuni and Campylobacter lanienae in feces of cattle by real-time quantitative PCR. Appl. Environ. Microbiol. 70, 2296-2306.

Jackson, C.R., Fedorka-Cray, P.J., Barrett, J.B., Ladely, S.R., 2004. Genetic relatedness of high-level aminoglycoside-resistant enterococci isolated from poultry carcasses. Avian Dis. 48, $100-107$.

Kim, Y.S., Kim, S.Y., Kim, J.H., Kim, S.C., 1999. Xylitol production using recombinant Saccharomyces cerevisiae containing multiple xylose reductase genes at chromosomal $\delta$ sequences. J. Biotechnol. 67, 159-171.

Klein, G., 2003. Taxonomy, ecology and antibiotic resistance of enterococci from food and the gastro-intestinal tract. Int. J. Food Microbiol. 88, 123-131.

Kurzak, P., Ehrmann, M.A., Vogel, R.F., 1998. Diversity of lactic acid bacteria associated with ducks. Syst. Appl. Microbiol. 21, $588-592$.

Lei, V., Jakobsen, M., 2004. Microbiological characterization and probiotic potential of koko and koko sour water, African spontaneous fermented millet porridge and drink. J. Appl. Microbiol. 96, 384-397.

Maciorowski, K.G., Nisbet, D.J., Ha, S.D., Corrier, D.E., DeLoach, J.R., Ricke, S.C., 1997. Fermentation and growth response of a primary poultry isolate of Salmonella typhimurium grown under strict anaerobic conditions in continuous culture and amino acidlimited batch culture. Adv. Exp. Med. Biol. 412, 201-208.

Mead, G.C., 2000. Prospects for 'competitive exclusion' treatment to control salmonella and other foodborne pathogens in poultry. Vet. J. 159, 111-123.

Mishra, C., Lambert, J., 1996. Production of antimicrobial substances by probiotics. Asia Pac. J. Clin. Nutr. 5, 20-24.

Nagata, Y., Yokota, H., Kosuda, O., Yokoo, K., Takemura, K., Kikuchi, T., 1985. Quantification of picogram levels of specific DNA immobilised in microtiter wells. FEBS Lett. $183,379-382$.

Niamsup, P., Sujaya, N.I., Tanaka, M., Sone, T., Hanada, S., Kamagata, Y., Lumyong, S., Assavanig, A., Asano, K., Tomita, F., Yokota, A., 2003. Lactobacillus thermotolerans sp. nov., a novel thermotolerant species isolated from chicken faeces. Int. J. Syst. Evol. Microbiol. 53, 263-268.

O'Sullivan, D.J., 2000. Methods for analysis of the intestinal microflora. Curr. Issues Intest. Microbiol. 1, 39-50.

Pereira, D.I., Gibson, G.R., 2002. Effects of consumption of probiotics and prebiotics on serum lipid levels in humans. Crit. Rev. Biochem. Biol. 37, 259-281.

Salanitro, J.P., Fairchild, I.G., Zgornicki, Y.D., 1974. Isolation, culture characteristics and identification of anaerobic bacteria from the chicken caecum. Appl. Microbiol. 27, 678-687.
Silvi, S., Rumney, C.J., Rowland, I.R., 1996. An assessment of three selective media for bifidobacteria in faeces. J. Appl. Bacteriol. 81, 561-564.

Soerjadi, A.S., Lloyd, A.B., Cumming, R.B., 1978. Streptococcus faecalis, a bacterial isolate which protects young chickens from enteric invasion by salmonella. Aust. Vet. J. 54, 549-550.

Spring, P., Wenk, C., Dawson, K.A., Newman, K.E., 2000. The effects of dietary mannanoligosaccharides on caecal parameters and the concentration of enteric bacteria in the ceca of salmonella-challenged broiler chicks. Poultry Sci. 79, 205-211.

Stern, N.J., Cox, N.A., Bailey, J.S., Berrang, M.E., Musgrove, M.T., 2001. Comparison of mucosal competitive exclusion and competitive exclusion treatment to reduce Salmonella and Campylobacter spp. colonisation in broiler chickens. Poultry Sci. $80,156-160$.

Stravic, S., 1992. Defined cultures and prospects. Int. J. Food Microbiol. 15, 245-263.

Stravic, S., Glesson, T.M., Blanchfield, B., 1991. Efficacy of undefined and defined bacterial treatments in competitive exclusion of salmonella from chicks. In: Blankenship, L.C. (Ed.), Colonization Control of Human Bacterial Enteropathogens in Poultry. Academic Press, San Diego, pp. 323-330.

Tannock, G.W., 1999. Analysis of the intestinal microflora: a renaissance. Antonie Van Leeuwenhoek 76, 265-278.

van der Vliet, G.M.E., Hermans, C.J., Klatser, P.R., 1993. Simple colorimetric microtitre plate hybridisation assay for detection of amplified Mycobacterium leprae DNA. J. Clin. Microbiol. 31, $665-670$.

van der Wielen, P.W., Biesterveld, S., Notermans, S., Hofstra, H., Urlings, B.A., van Knapen, F., 2000. Role of volatile fatty acids in development of the caecal microflora in broiler chickens during growth. Appl. Environ. Microbiol. 66, 2536-2540.

Vassileva, A., Chugh, D.A., Swaminathan, S., Khanna, N., 2001. Expression of hepatitis B surface antigen in the methylotrophic yeast Pichia pastoris using the GAP promoter. J. Biotechnol. $88,21-35$.

Wagner, R.D., Holland, M., Cerniglia, C.E., 2002. An in vitro assay to evaluate competitive exclusion products for poultry. J. Food Prot. 65, 746-751.

Weinack, O.M., Snoeyenbos, G.H., Soerjadi-Liem, A.S., 1985. Further studies on competitive exclusion of Salmonella typhimurium by lactobacilli in chickens. Avian Dis. 29, 1273-1276.

Wierup, M., Wold-Troell, M., Nurmi, E., Hakkinen, M., 1988. Epidemiological evaluation of the salmonella-controlling effect of a nationwide use of competitive exclusion culture in poultry. Poultry Sci. 67, 1026-1033.

Zhu, X.Y., Zhong, T., Pandya, Y., Joerger, R.D., 2002. 16S rRNAbased analysis of microbiota from the cecum of broiler chickens. Appl. Environ. Microbiol. 68, 124-137. 